\title{
Urgences
}

\section{Mario Cotté, Pinipède le blanchon, Sherbrooke, Naaman, 1983.}

\section{Lucie Gauvin}

Numéro 8, 4e trimestre 1983

Littérature jeunesse

URI : https://id.erudit.org/iderudit/025127ar

DOI : https://doi.org/10.7202/025127ar

Aller au sommaire du numéro

Éditeur(s)

Urgences

ISSN

0226-9554 (imprimé)

1927-3924 (numérique)

Découvrir la revue

Citer ce compte rendu

Gauvin, L. (1983). Compte rendu de [Mario Cotté, Pinipède le blanchon,

Sherbrooke, Naaman, 1983.] Urgences, (8), 120-122.

https://doi.org/10.7202/025127ar

Ce document est protégé par la loi sur le droit d'auteur. L’utilisation des services d'Érudit (y compris la reproduction) est assujettie à sa politique d'utilisation que vous pouvez consulter en ligne.

https://apropos.erudit.org/fr/usagers/politique-dutilisation/
Cet article est diffusé et préservé par Érudit.

Érudit est un consortium interuniversitaire sans but lucratif composé de l’Université de Montréal, l'Université Laval et l'Université du Québec à Montréal. Il a pour mission la promotion et la valorisation de la recherche. https://www.erudit.org/fr/ 
PINIPĖdE LE BLANCHON, de Mario Côté, ed. Naaman, dessins de Paul-Henri Dubé.

L'enfant qui lit ou écoute la lecture de Pinipède le Blanchon peut-il de quelque manière s'y reconnaître? Ce qui est une autre façon de dire: ce texte est-il significatif pour les enfants dont nous nous occupons?

La réponse la plus pertinente serait celle que révèle l'analyse des réactions de l'enfant à la présentation, à la lecture et à l'après-lecture du livre. Ce que je n'ai pas eu le loisir de faire et qui vaut pourtant mieux que bien des analyses d'adultes. $\dot{A}$ défaut d'avoir pu procéder à cette étape, j'invite les éducateurs et éducatrices de la maison et de l'école à le faire et à communiquer leurs observations à l'auteur.

Je me permets de vous donner à cet égard des indices du comportement de l'enfant que je trouve utiles de mettre en relation pour juger de son intérêt pour un récit. Qu'observe-t-on relativement

- aux motifs qui incitent l'enfant à lire ou à écouter la lecture de Pinipède qu'on vient de lui offrir ou de mettre à sa disposition?

- à sa façon de réagir au premier contact avec le livre en question que l'enfant choisit d'entendre ou de manipuler ou de lire?

- aux commentaires ou aux questions que l'enfant fait ou pose avant même de connaître le contenu du livre?

aux premières réactions suite à la présentation que l'adulte ou qu'un (e) aîné (e) lui en fait?

- à sa façon de se tenir, ses gestes, les manifestations d'intérêt ou d'ennui et les moments où ces indices sont perçus par l'adulte?

- aux propos qu'il tient sur le récit lu ou entendu, sur les illustrations, sur la présentation matérielle du livre, ses questions ou critiques, ses comparaisons ou rapprochements avec ce 
qu'il connaît et aime?

L'ensemble de ces observations mises en relation sont, je crois, susceptibles de révéler la portée du défi que Mario Côté s'est donné en créant cette histoire, vraie ou pas vraie, d'un blanchon pour qui tout n'est pas rose. Fort du support de sa meute, d'abord maladroit et audacieux comme ceux et celles qui en sont à leurs premiers printemps, le blanchon de I'Ungava ose, explore, apprend à ses risques et périls, se distingue par sa perspicacité et accepte finalement la responsabilité de diriger sa bande.

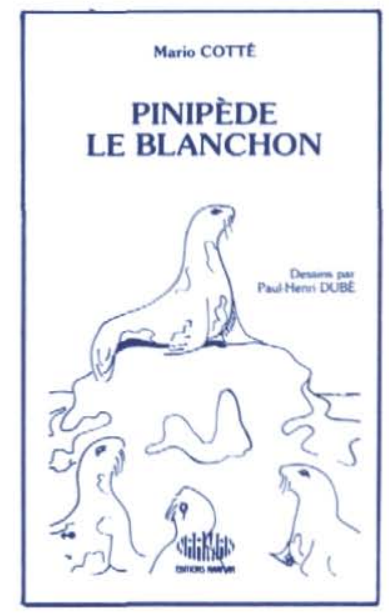

Le récit est coupé en quatre séquences ou épisodes qui, dans l'ordre, situe Pinipède dans son environnement, le révèle s'initiant à la mer, nous le montre en désarroi devant le massacre de ses frères, et enfin, engagé lui-même dans des exploits contre l'ennemi pour la survie des siens.

Chaque épisode constitue en lui-même une unité; I'enfant peut ainsi soulager sa mémoire tout en se donnant des repères qui ponctuent l'évolution du blanchon. Ce récit prépare bien l'enfant intéressé par les phoques à aborder un documentaire sur le sujet ou à faire part à ses pairs de l'aventure d'un de ces personnages-amis avec qui il a noué une relation. 
Si les valeurs que véhicule ce livre le rejoignent, si la description ne l'écarte pas de la narration, si son goût du mouvement ou de l'aventure et si ses inquiétudes devant la vie trouvent leur compte, I'enfant s'attachera à Pinipère devenu source de piasir.

Bravo à son auteur. Bonne lecture aux grands et aux petits.

Lucie Gauvin, Département des sciences de I'Education, UQAR

$* * * * *$

LE PĖRE NOËL A-T-IL OUBLIÉ LE BAS DU FLEUVE?, Roseline Grand-Maison et Michel Caillouette, Naaman, 1983.

Pour faire un commentaire critique sur un conte pour enfants, doit-on tenter de se placer dans la perspective du lecteur ciblé ou jeter un regard d'adulte sur une écriture d'adulte destinée aux enfants? Selon l'optique choisie la nature du jugement peut s'en trouver profondément modifiée.

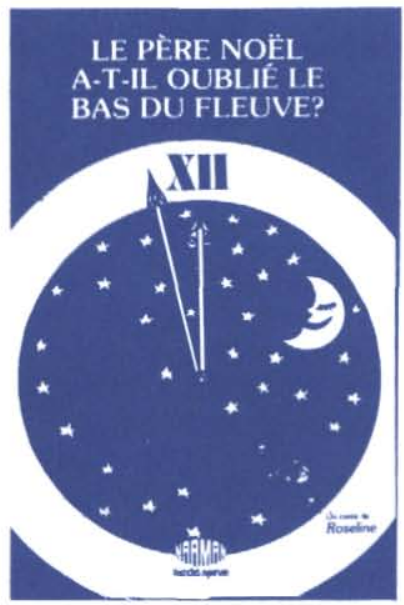

Comme on l'a déjà signalé dans les pages d'URGENCES, il faut avoir écrit (ou essayé de le faire) pour (ce qui diffère de par et 